\title{
Simulations of Starting and Braking of the Chainsaw
}

\author{
Lubomír Pešík*, Antonín Skarolek \\ Technical University of Liberec, Faculty of Mechanical Engineering, Studentská 2, 46117 Liberec, Czech Republic
}

\section{KEY WORDS}

Chainsaw, Dynamic conditions, Starting, Emergency braking.

\begin{abstract}
Chainsaws are devices that exhibit intense dynamic effects. Their duty cycle can be divided into several stages. In particular: start-up, operational run and run-down. During each stage the engine unit is connected to or disconnected from the working part through centrifugal clutch. When driven by internal combustion engine, the unfavourable vibrations occur at the handles due to unevenness of its run. Chainsaw manufacturers pay special attention to emergency braking in critical situations. Time necessary for chain to stop from encountering the first emergency trigger is taken as a measure of effectiveness of the breaking system. To assess specific chainsaw systems, it is necessary to create detailed computational dynamic model.
\end{abstract}

\section{INTRODUCTION}

At the present time, the chainsaw manufacturers are not only focused on minimizing of vibration transferred to the operators' hands, but also on effectiveness of emergency braking systems allowing rapid stop of the chain when critical conditions occur. Band brakes are used for these purposes. The braking effect depends mainly on the contact force of the band and the friction between the band and the drum. The diameter of the drum is usually driven by design requirements and cannot be arbitrarily enlarged. However, the joint action of the brake and the clutch-disconnecting the engine unit from the working unit of the chainsaw- is of particular importance. The immediate reduction of the inertial torque of the braked system leads to the significant reduction of time needed to stop the chain. The starting point of research on vibration minimizing and chain braking is a dynamic model of chainsaw. The correctly built model is particularly important for chainsaws that are powered by combustion engine. In this case -unlike the case of electric systems- not only the unevenness of the driving torque, but also the periodic variations of the moment of inertia of the moving parts have to be considered [1], [2]. The required values of parameters of the chainsaw system can be obtained either by means of experiments or from the 3D design documentation. Determination of the driving forces lies in the measurement of pressure in the combustion chamber of the engine. The pressure is measured in dependence on angular position of the crankshaft running at different operation speeds. From these data, and from the design parameters of the crankshaft mechanism, drive torque of the engine can be obtained as a time dependent function [3].

\section{Mechanical model}

The moving parts of chainsaw involve combustion engine, flywheel with incorporated fan, centrifugal clutch drum, which is wrapped around by a band (not shown) with a wrap angle of $2 \pi$. The clutch connects the engine to the chain sprocket that drives the chain (Figure 1). 


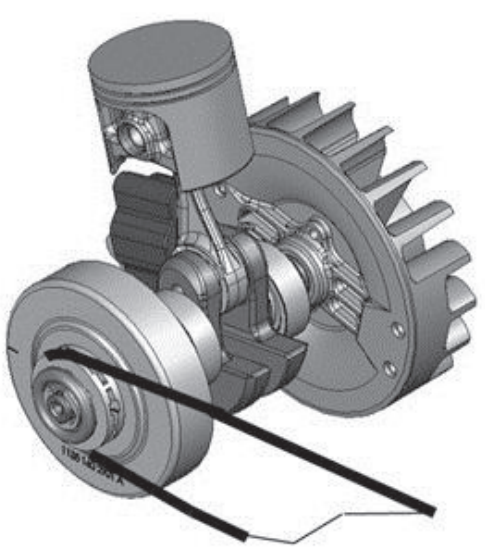

Fig. 1: Moving assembly of the saw.

The moving assembly of the chainsaw can therefore be divided into two subassemblies; former consisting of the engine with the fan and the inner part of centrifugal clutch, and the latter that comprises the outer part of the centrifugal clutch, which is the braked drum with attached sprocket and the chain (Figure 2).

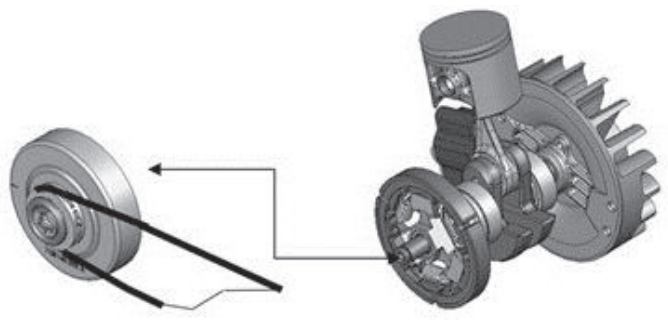

Fig. 2: Two parts of moving assembly of the saw.

The gas pressure acts upon piston of the engine and generates the torque, which is shown in the figure 3 as a function of the angular position of the crank-shaft [4], [5], [6].

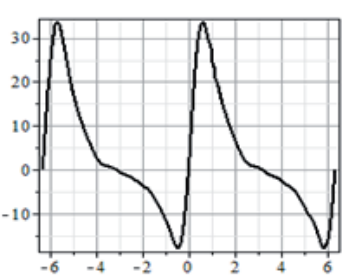

a)

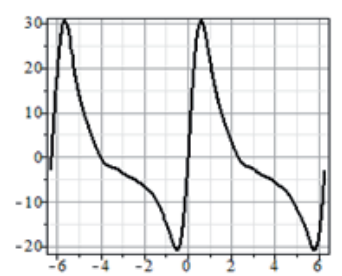

b)
Fig. 3: Engine torque - a) Total, b) Dynamic component.

When reaching the angular velocity of crankshaft
$\boldsymbol{\omega}_{\mathbf{M}}=\mathbf{6 0 0}$ rad.s. ${ }^{-1}$, the drum with sprocket and chain starts to connect to the crankshaft through centrifugal clutch by means of frictional joint. The clutch will then transmit torque that can be calculated as

$$
\begin{aligned}
& M_{K}(t)=3 \cdot\left(\frac{1}{2} D_{K} m_{K} \omega_{M}^{2}-F_{K F}\right) . \\
& \cdot f_{K} \frac{1}{2} D_{K} \cdot\left[\frac{1}{2}\left(\tanh \left(\omega_{M}-\omega_{R}\right)+1\right)\right] . \\
& \cdot\left[\frac{1}{2}\left(\tanh \left(100\left(\omega_{M}-600\right)\right)+1\right)\right] .
\end{aligned}
$$

The equation of motion can be written as

$J_{M} \frac{\mathrm{d}^{2} \varphi_{M}}{\mathrm{~d} t^{2}}+\frac{1}{2} \frac{\mathrm{d} J_{M}}{\mathrm{~d} \varphi_{M}}\left(\frac{\mathrm{d} \varphi_{M}}{\mathrm{~d} t}\right)^{2}=$

$=M_{d}(t)-M_{K}(t)$

The drag torque of the chain as a function of the square of angular velocity of the sprocket can be expressed in the form

$$
M_{W}(t)=M_{w s} \omega_{R}^{2}\left(2 \pi \frac{{ }^{n} M \max }{60}\right)^{-2}
$$

Maximum value Mws of this torque occurs at the highest engine speed; this value is equal to the average value of the engine torque.

During braking by the band brake triggered at the time $t=2 s$, the braking torque is added to the rotating system. The value of the brake torque can be expressed as

$$
\begin{aligned}
& M_{B}(t)=R_{B} F_{B}\left(e^{2 \pi f_{B}}-1\right)\left[\frac{1}{2}(\tanh (100(t-2))+1)\right] . \\
& \cdot\left[\frac{1}{2}(\tanh (\omega R)+1)\right]
\end{aligned}
$$

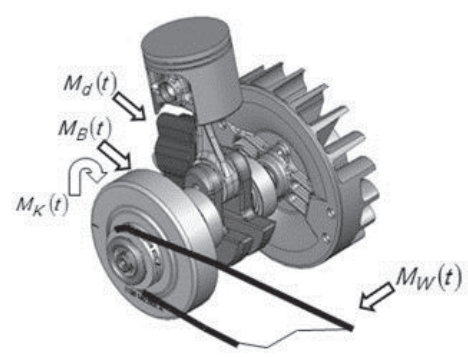

Fig. 4: Moving assembly of the saw.

Equation of motion of the system under braking condition is now:

$J_{R} \frac{d^{2} \varphi_{R}}{d t^{2}}=M_{K}(t)-M_{B}(t)-M_{W}(t)$ 
The system of equations of motion (2) and (5) can be solved by use of computational program such as Maple, thus getting the time domain solution of run-up and emergency brake phases (Figure 5); with initial conditions:

$\omega_{R}(0)=0, \omega_{M}(0)=300, \varphi_{R}(0)=0, \varphi_{M}(0)=0$ (6)
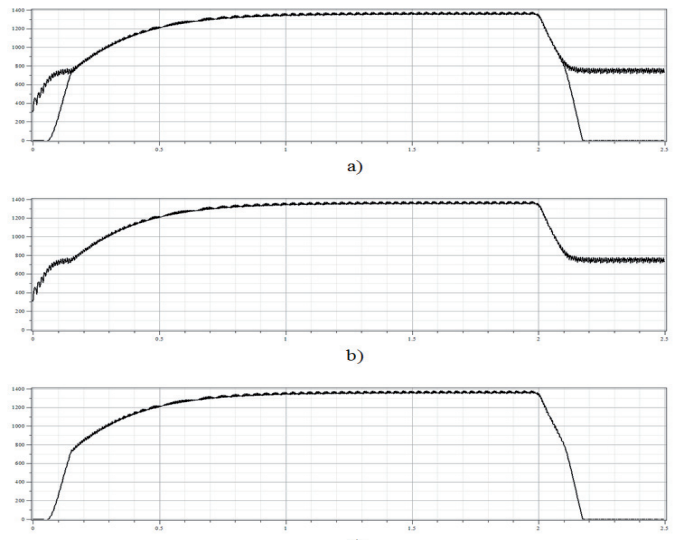

Fig. 5: Time domain solution; velocities: a) whole assembly $\omega \mathrm{M}(\mathrm{t})$, $\omega_{\mathrm{R}}(\mathrm{t})$, b) motor assembly $\left.\omega_{\mathrm{M}}(\mathrm{t}), \mathrm{c}\right)$ chain assembly $\omega_{\mathrm{R}}(\mathrm{t})$

\section{Conclusion}

Presented dynamic model of chainsaw allows examination of the formation and transmission of mechanical vibration to the operator's hands and helps effectively minimize the vibration by vibration isolation counter-measures. The model is divided into two parts; the driving and the driven one. In addition, it is possible to simulate chainsaw behaviour through its duty cycle, e.g. start-up of the engine and its connection to the chain unit via centrifugal clutch. An important finding, which can be obtained by the numerical model, is the load capacity of centrifugal clutch at a condition of peak power load of the chainsaw. Special attention is paid to the product safety by chainsaw designers. Safety of the chainsaw corresponds with the time needed for chain to be stopped by the emergency band brake. These considerations can be judged with help of developed numerical model.

\section{References}

[1] Pešík, L., Vančura, M.: Vibration Isolation Support of Machine with Flexible Frame. In Proceeding of the 50. International scientific conference of machine elements departments. 1st edition. Žilina: University of Žilina - EDIS - edition ŽU, 2009. s. 47. ISBN 978-80-554-00.
[2] Pešík, L., Vančura, M.: Vibration of hand tool. In Proceeding of 27. International scientific conference DIAGO 2008 : Technical University of Ostrava, 2008. ISSN 1210-311X.

[3] Pešík, L., Vančura, M.: Antivibration System of Hand-Held Tools with Dominant Vibration Component. In 48th International Conference of Machine Elements and Mechanisms Department 2007. Bratislava: Slovak technical University of Bratislava, 2007. s. 42. ISBN 978-80-227-27.Surname N.M., Surname, N. and Surname N., Name of Book (in Italics) (Publisher, Place of Publication, YYYY). ISBN.

[4] Pešík, L., Skarolek, A.: Tuning of Vibration Isolation Differential Pneumatic System by Means of Trottle Valve. In Transactions of the Universities of Košice: Research reports from the Universities of Košice. 2nd edition. Košice :Technical University of Košice, 2011. s. 191-196. ISSN 1335-2334.

[5] Pešík, L., Skarolek, A.: Variable Stiffness of Resilient Pneumatic Support. Pneumatyka: Przemysłowe systemy spręzonego powietrza. 2011, 78, 1, s. 25-27. ISSN 1426-6644.

[6] HARRIS, C. M. Shock and vibration handbook. New York: McGraw-Hill, 2002.

[7] Homišin, J.: Methods of tuning torsionally oscillating mechanikal systems using pneumatic tuners of torsional oscillations. Transactions of the technical university of Kosice, 3/4, 1993, p. 415-419.

[8] Homišin, J. a kol.: Súčasné trendy optimalizácie strojov a zariadení. Košice: C - PRESS, 2006. 
Acta Mechanica Slovaca

Journal published by Faculty of Mechanical Engineering - Technical University of Košice

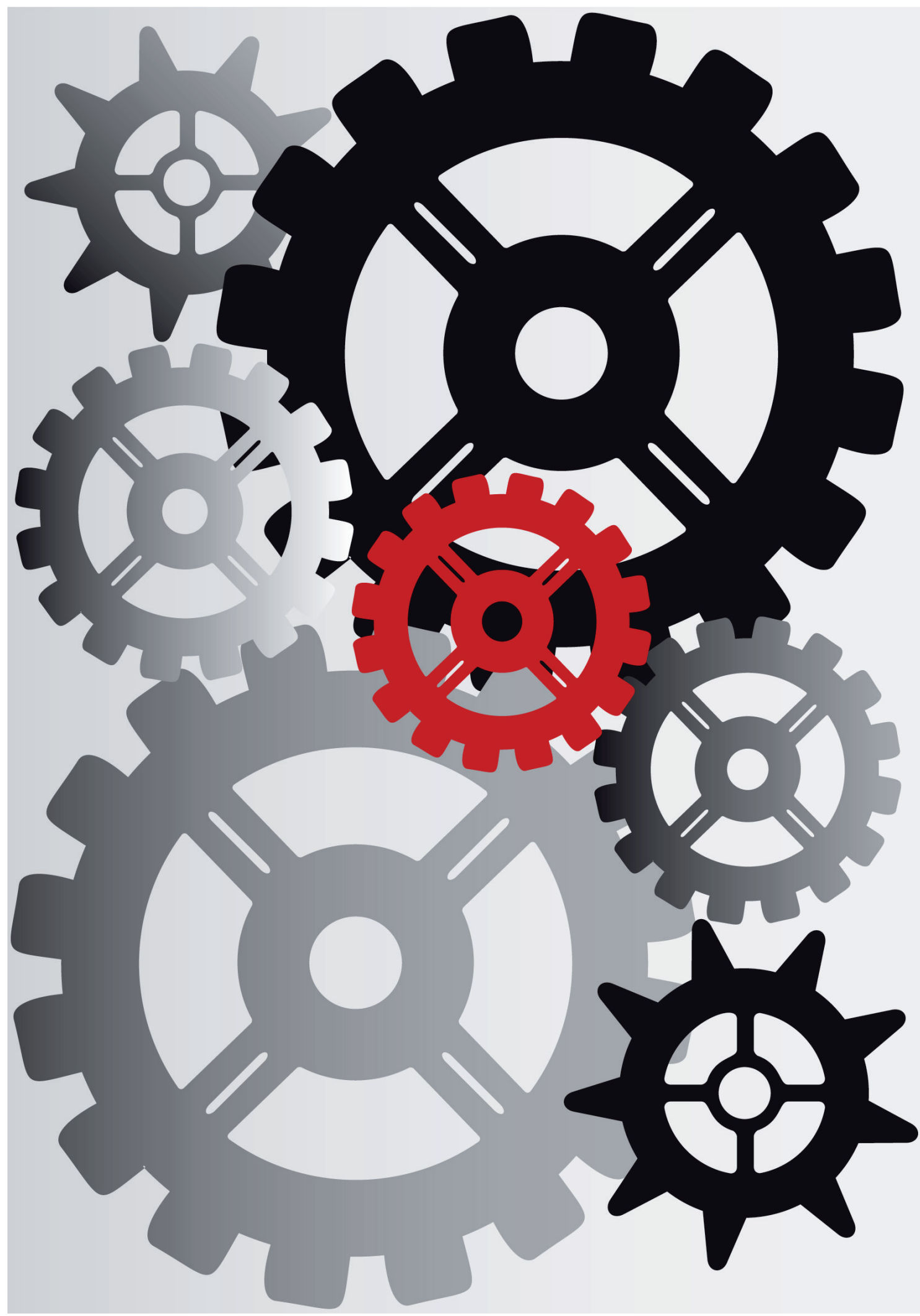

